Int. J. Dev. Biol. 49: 665-674 (2005)

doi: $10.1387 / \mathrm{ijdb} .052028 \mathrm{ce}$

\title{
Plant tropisms: providing the power of movement to a sessile organism
}

\author{
C. ALEX ESMON, ULLAS V. PEDMALE and EMMANUEL LISCUM* \\ University of Missouri-Columbia, Division of Biological Sciences, Columbia, Missouri, USA
}

\begin{abstract}
In an attempt to compensate for their sessile nature, plants have developed growth responses to deal with the copious and rapid changes in their environment. These responses are known as tropisms and they are marked by a directional growth response that is the result of differential cellular growth and development in response to an external stimulation such as light, gravity or touch. While the mechanics of tropic growth and subsequent development have been the topic of debate for more than a hundred years, only recently have researchers been able to make strides in understanding how plants perceive and respond to tropic stimulations, thanks in large part to mutant analysis and recent advances in genomics. This paper focuses on the recent advances in four of the best-understood tropic responses and how each affects plant growth and development: phototropism, gravitropism, thigmotropism and hydrotropism. While progress has been made in deciphering the events between tropic stimulation signal perception and each characteristic growth response, there are many areas that remain unclear, some of which will be discussed herein. As has become evident, each tropic response pathway exhibits distinguishing characteristics. However, these pathways of tropic perception and response also have overlapping components - a fact that is certainly related to the necessity for pathway integration given the everchanging environment that surrounds every plant.
\end{abstract}

KEY WORDS: phototropism, gravitropism, thigmotropism, hydrotropism

When circumstances become unfavorable for optimal growth and development of animals, they can respond accordingly by moving to a more favorable environment. Plants are not afforded this luxury. Due to their sessile nature, plants are forced to make the most of their immediate surroundings, which means adapting to an ever-changing environment (Liscum, 2002). Darwin described some of these responses to environment more than a century ago in his book The Power of Movement in Plants (Darwin, 1880). Darwin noted that plants had a tendency to sense their environment so as to orient themselves for optimal growth and development.

Plants are constantly being bombarded with changes in their environment. Temperature fluctuations, poor light and low water content in the soil are just a few of the factors to which plants must be able to respond. Moreover, plants must respond to physical forces of nature such as gravity or touch stimulation. Over evolutionary time, plants have adapted to their surroundings with a high degree of plasticity, affording them the ability to respond to everchanging conditions that provide constant stimulation. Plant tropisms are operationally defined as differential growth responses that reorient plant organs in response to direction of physical stimuli. Tropisms can be negative, such as a stem bending away from a gravity stimulation (Blancaflor and Masson, 2003), or they can be positive, as in a stem bending toward a light stimulation (Liscum, 2002). Tropisms are different from nastic plant movements, such as the diurnal movement of leaves or the opening and closing of flowers, in that nastic growth is not directional in relation to a stimulation (Findlay, 1984). With tropic growth, the direction of the stimulation is very important.

Although it has been shown that each tropic response is governed by generally divergent genetic systems, it has become evident in recent years that at least some of the mechanistic features inherent to tropic responses may be shared. It is also apparent that different tropic responses function in coordinating and overlapping ways to give rise to adaptive responses necessary for normal plant growth and development. So how are very different physical stimulations, or inputs, perceived and responded to in such a way to yield outputs - differential growth responses - that are virtually the same? As we are finding in most areas of biology, nothing functions in vacuum. Much of the overlap has to do with the action of plant hormones and how each modulates cell growth. In each case it appears that it is the redistribution of plant hormones 
in response to signal perception that precedes and likely stimulates the differential growth response.

As already mentioned the operational definition of a tropic response is the curve of a plant organ toward or away from a directional stimulation. This can only be accomplished through a differential growth response in which certain cells are actively elongating at a greater rate in one region of the responding organ relative to an opposing position within that same organ. As most work in the area of tropic response has shown, curvature can only be properly manifested through the coordinated activity of hormones. Small fluctuations in the cellular concentration of hormones can have a drastic effect on whether or not a cell is going to rapidly expand or continue to grow at a normal growth rate.

While plants do not exhibit cell migration-the one example being pollen tube growth-they do have the ability to move hormones and other signal molecules between cells as well as over long distances. In plants, the story is this: The cell may not move, but the signal can. In animal systems, hormones may or may not work at the site they are synthesized, but this is not always the case in plant systems. Auxin, for example, is synthesized in the shoot apex but is effective as a morphogen from "tip to tail" (or from shoot apex to root apex). The specific cellular concentration is what will determine what effect the hormone will have at a particular time and place. As in real estate, it's location that matters.

Just like animals, plant hormones are small organic molecules that are most effective at certain concentrations on a cell-to-cell basis. Hormones, being potent growth regulators, tend to be most effective in promoting growth and development at small concentrations. Indeed, large concentrations of certain plant hormones such as auxin or ethylene can actually be growth retarding. But hormones aren't the whole story. Each tropic response has its own special suite of molecules that are necessary for proper signal perception, signal amplification and attenuation and elaboration of the growth response. While the establishment of hormone gradients is a required step in each response, it's not the hormone that does the dirty work. Auxin, for example, acts indirectly through many different proteins to induce a growth response.

Plants have evolved to respond to a variety of environmental circumstances. This review will focus on the four best-characterized tropic responses: phototropism (response to directional light), gravitropism (response to gravity stimulation), thigmotropism (response to touch) and hydrotropism (response to water availability).

\section{I saw the light}

Phototropism is the directional growth of a plant organ toward (or away from) a blue-light stimulation. Stems exhibit positive phototropism (growth towards the stimulation), while roots exhibit negative phototropism (growth away from the stimulation). As proposed, this occurs because of a greater rate of cellular elongation on the shaded side of the plant as opposed to the rate on the lit side. This phenomenon has been documented for more than 140 years. In the 19th Century, Darwin postulated that there was "something" being moved from the tip of the plant to the shoot that enabled it to bend toward the light stimulation. In the early portion of the 20th Century, Cholodny (1927) and Went and Thimann (1937), working independently, proposed that it was due to a redistribution of a growth-promoting substance from one side of a plant to the other that lead to the phototropic response. They named this substance "auxin" which is Greek for "to increase" - an appropriate name given its properties to promote cell elongation. It would be many years before the substance was purified and a structure determined, but auxin would become the first plant substance to be termed a "hormone."

How does the perception of photons of light energy lead to a differential growth response that is potentially based on a hormone gradient? First the photons must be perceived by the plant. Blue light-induced phototropic responses utilize a class of chromoproteins known as the phototropins (Figure 1). While other families of photoreceptors such as the phytochromes (Parks et al., 1996; Janoudi et al., 1997) and cryptochromes (Whippo and Hangarter et al., 2003) have been shown to play varying roles in phototropic responses, only the actions of the predominant phototropins will be discussed here. Moreover, most of the genetic and physiological studies discussed here will be limited to those performed in the model plant Arabidopsis thaliana.

There are two phototropins in Arabidopsis, designated PHOT1 and PHOT2. PHOT1 was the first of the phototropins to be identified through a screen for mutants that showed impaired phototropic curvature under low-fluence rate blue light (Liscum and Briggs, 1995). Under high fluence blue light, however, phot1 mutants exhibited a normal phototropic response, indicating the action of another photoreceptor under high light conditions (Sakai et al., 2000). The most obvious candidate for a second receptor would be one related to PHOT1. PHOT2 was initially identified through sequence homology to PHOT1 (Jarillo et al., 1998). Its potential role as the second phototropic receptor was cemented when Sakai and colleagues (2001) determined that phot1phot2 double mutants lack phototropic response in both low and high fluence rate blue light. However, phot2 single mutants retained an essentially wildtype response under all fluence rates tested (Sakai et al., 2001). It was therefore concluded that phot1 and phot2 function redundantly as high light receptors, while phot 1 acts as the low-light photoreceptor (Sakai et al., 2001). The phototropins are members of a larger family of sensor proteins known as the LOV domain family (Crosson et al., 2003). The family name is derived from the function of the LOV domain as a sensor for light, oxygen or voltage (Huala et al., 1997, Zhulin and Taylor, 1997; Taylor and Zhulin, 1999; Crosson et al., 2003). Each photoropin contains two LOV domains, termed LOV1 and LOV2 (Huala et al., 1997). The non-phototropin members of the LOV family contain just a single LOV domain (Crosson etal., 2003). The phototreceptive properties of the photoropins is derived from the non-covalent binding of one flavin mononucleotide (FMN) molecule to each of its LOV domains (Christie et al., 1998; Figure 1). Phototropins are activated through light absorption and subsequent formation of a covalent adduct between the conserved C(4)a atom of the FMN and a conserved cysteine residue within the LOV domain. This adduct formation is thought to initiate downstream signaling through de-repression of the carboxy terminal serine/threonine kinase domain of the phototropin (Christie et al., 2002; Harper et al., 2003, 2004; Figure 1). Interestingly, there are differences in the functional properties of each LOV domain within a given phototropin. Amino acid replacement experiments performed with either the LOV1 or LOV2 domain of phot 1 demonstrated that within phot1, only LOV2 abduct formation is necessary for phototropic function (Christie et al., 2002). To date, no clear function has been assigned to the LOV1 domain although recent studies by Salomon and colleagues (2004) 
suggest that LOV1 may serve as a dimerization domain.

The de-repression of the kinase domain of the phototropins would seem to imply a role for protein phosphorylation in the transduction of the active signal to downstream events necessary for altered growth and development with respect to the phototropic response. There are currently no known phosphorylation substrates for the phototropins aside from the phototropins themselves (Liscum, 2002; Briggs and Christie, 2002). Phototropin interacting partners have been identified. The first phot1-interacting protein to be identified was NPH3 (Motchoulski and Liscum, 1999; Figure 2). nph3 was another mutant isolated in the same screen that yielded phot1 (Liscum and Briggs, 1995) with null mutations in NPH3 showing a complete loss of phototropic response (Liscum and Briggs, 1996; Motchoulski and Liscum, 1999). NPH3 turns out to be a member of a large 33-member family Arabidopsis, designated the $N R L$ (NPH3/RPT2-like) gene family (Motchoulski and Liscum, 1999; S. Joo and E. Liscum, unpublished). While most members of the $N R L$ family exhibit a conserved domain structure (Motchoulski and Liscum, 1999; Sakai et al., 2000; E. Liscum, unpublished), the protein structure of NPH3 provides little clue about a potential biochemical function. It has been hypothesized that NPH3 acts as a scaffolding or adaptor protein to assemble a signaling complex containing phot1 and other unidentified proteins at the plasma membrane (Motchoulski and Liscum, 1999). A critical role for NRL proteins in phototropism is further suggested by the finding that mutations in RPT2 also lead to phototropic defects (Okada and Shimura, 1992, 1994; Sakai et al., 2000) Moreover, RPT2, like NPH3, interacts with phot1 (Inada et al., 2004; Figure 2). RPT2 has also been shown to form heterodimers with NPH3, suggesting a dynamic and complicated signaling complex (Inada et al., 2004; Sakai et al., 2000). This plasma-membrane-associated complex could be directly coupled to changes in auxin transport that might be regulated via changes in phosphorylation status (Celaya and Liscum, 2005; Stone et al., 2004; Figure 2).

For more than 100 years, scientists have centered the differential growth necessary for the phototropic curve squarely on the
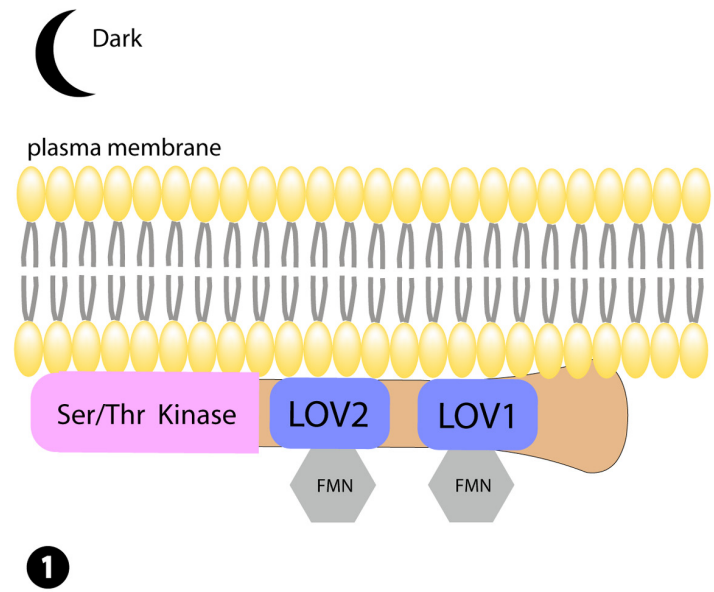

shoulders of auxin. This dependence on auxin is best typified by the Cholodny-Went hypothesis (Cholodny, 1927; Went and Thimann, 1937). In brief, this hypothesis holds that increases in auxin concentration in the shaded flank (relative to the opposing lit flank) of a phototropically-stimulated stem (Figure 2) would result in a shoot that bends toward the light due to auxin-induced growth (Cholodny, 1927; Went and Thimann, 1937). Such a differential accumulation of auxin requires active movement of the hormone. As already mentioned, the plasma-membrane-associated complex including phot1 and other proteins (such as NPH3 or RPT2) could influence auxin transport. A phot1-signalling complex could be working through modification of auxin transporter localization. For example, Blakeslee and colleagues (2004) have recently found that upon blue-light stimulation, PIN1, a facilitator of polar auxin transport (Geldner et al., 2001), delocalizes from the basal wall of the plant cell and that this delocalization does not occur in cells of phot 1 null mutants (Blakslee et al., 2004; Figure 2).

What happens once the auxin reaches the shaded side of the plant? In the same screen that yielded phot1 and nph3, a third aphototropic mutant, nph4, was recovered (Liscum and Briggs, $1995,1996)$ that shows severely altered auxin responsiveness (Watahiki and Yamamoto, 1997; Stowe-Evans et al., 1998). NPH4 was cloned and found to encode the auxin-responsive transcription factor ARF7 (Harper et al., 2000) ARF7 is a member of a multigene family in Arabidopsis, consisting of as many as 23 members (Liscum and Reed, 2002). The finding that an auxin-responsive transcription factor is necessary for proper phototropic curvature gives credence to the long held notion that the phototropic response is based on an auxin gradient and further suggest that changes in gene expression are a necessary component of the phototropic response system (Liscum, 2002; Figure 2).

ARFs can be either transcriptional repressors or transcriptional activators, depending on their variable middle region (MR). ARF7 contains a Q-rich middle MR often associated with transcriptional activators and has indeed been shown to function as an activator (Tiwari et al., 2003). ARF proteins also contain a C-terminal dimerizartion domain (CTD) that allows them to homodimerize or

Blue light irradiation

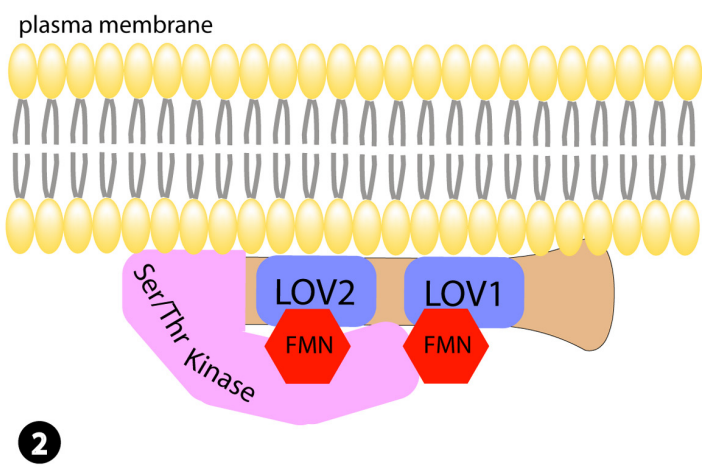

Fig. 1. Model of blue light-dependent activation of phototropins. Arabidopsis phototropins are plasmalemma associated proteins containing conserved LOV (light, oxygen or volatage) domains which are part of the PAS superfamily and a serine/threonine kinase domain. In the dark one flavin mononucleotide (FMN) is bound non-covalently to each of two LOV domains (left panel) and are activated under blue light irradiation (right panel). LOV domains form covalent adduct with the C(4)a atoms of FMN thus initiating downstream signaling through de-repression of carboxy Ser/Thr kinase domain. It has been revealed that these novel phototropins are their own substrates thus undergoing autophosphorylation and initiating cascade of phototropic signaling events. 
heterodimerize with other ARF family members or to heterodimerize with Aux/IAA family members that share the C-terminal dimerization domain (Ulmasov et al., 1999; Hagen and Guilfoyle, 2002; Tiwari et al., 2003). Lastly, ARF protiens contain a DNA binding domain (DBD) that exhibits homology to the VP1 class of transcription factors (Ulmasov et al., 1999) and allows ARFs to bind to auxin response elements (AuxREs), which can be found in the promoter region of target genes (Ulmasov et al., 1997). There is currently very little known about the function of most ARF family members other than NPH4/ARF7 with the exception of a small handful. Through loss of function mutant analysis we know that ETTIN(ET)/ $A R F 3$ is necessary for auxin-dependent pattern formation of the gynoecium (Nemhauser et al., 2000; Sessions et al., 1997) and that MONOPTEROS(MP)/ARF5 plays a role in vascular tissue patterning and differentiation (Hardtke and Berleth, 1998).

How is ARF function connected to auxin? Liscum and Reed (2002) have presented a relatively simple model to explain auxinregulated ARF function. First, ARFS are thought to bind to AuxREs of target genes as inactive heterodimers with Aux/IAA proteins (Tiwari et al., 2001, 2004; Figure 2). Next, as the auxin concentration rises, turnover of the IAA proteins occurs via SCF ${ }^{\text {TIR1 }}$ dependent proteoelysis (Gray et al., 2001; Ramos et al., 2001; Zenser et al., 2001, 2003; Kepinski and Leyser, 2004), allowing ARF-ARF heterodimers to form resulting in active complex (Figure 2). An ARF-ARF7 complex could thus lead to the increased (or decreased in case of repressor ARFS) transcription of target genes in response to increased auxin levels (Liscum and Reed, 2002; Figure 2). Interestingly, ARF7 seems to be targeting its own repressor in the hypocotyl, IAA19 (Tatematsu et al., 2004) a member of the early auxin response Aux/IAA family of proteins
(Theologis etal., 1985). Dominant mutations in IAA19 that stabilize the resultant protein lead to an aphototropic phenotype reminiscent of nph4 (Tatematsu et al., 2004). This is in agreement with biochemical results that suggest dominant mutations in Aux/IAA family members lead to a decrease in auxin-stimulated transcription (Tiwari etal., 2001). By increasing the stability of IAA19, protein turnover through the proteosome is decreased and IAA19 remains bound to ARF7, leaving the complex inactive in an increased auxin environment.

But what are the potential targets of NPH4/ARF7 transcriptional activity, besides IAA19/MSG2 ? Given that the output of the phototropic response is a differential growth response based on differing rates of cell elongation, potentially the targets are enzymes either directly or indirectly involved in loosening of the cell wall (Stone et al., 2004; Figure 2). NPH4/ARF7 could be acting on primary or secondary expansion molecules. This would allow for a greater rate of cell elongation on the shaded side as opposed to the lit side. Some candidate genes might be members of the $\alpha$ expansin family (Cosgrove, 2000) or perhaps members of the $\mathrm{GH} 3$ and SAUR gene families (Hagen and Guilfoyle, 2002). Interestingly, there are AuxREs in the promoter regions of all the previously mentioned gene families (Hagen and Guilfoyle, 2002). What remains unknown is whether NPH4/ARF7 is directly activating genes involved in cell wall modification or if it is activating other transcription factors that in turn may be acting on the cell wall modification enzymes. It is also possible that NPH4/ARF7 is acting in conjunction with another ARF family member through the CBD to lead to transcription of given target genes. Recently, it was reported by Tian and colleagues (2004) that mutations in the ARF8 gene showed a slight decrease in phototropic response (about $20 \%$ in

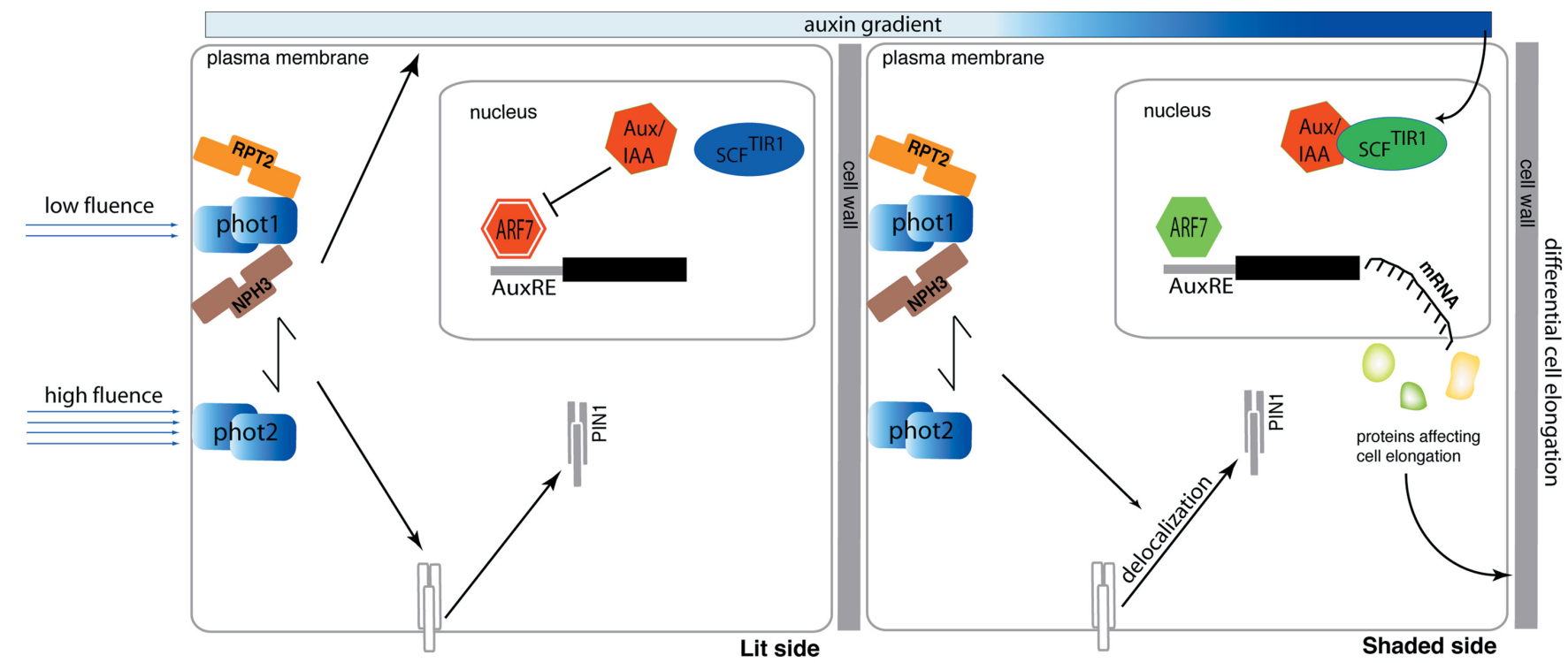

Fig. 2. Scheme of signaling pathway mediated by phototropin associated complex leading to phototropism. Phototropins (phot 1 and phot2) are known to act redundantly as high-light receptors, while phot1 acts as a low-light photoreceptor. NPH3 and its homologue RPT2 are plasma membrane associated proteins known to physically interact with the phot1, thus forming a photo-signaling complex. Under blue light irradiation this phototropincomplex undergoes change in phosphorylation states on the lit side leading to unequal lateral auxin gradient through the tissue with higher auxin concentration in the shaded side (gradient bar, top). This buildup of auxin on the shaded side initiates the SCF ${ }^{T I R 1}$ based proteasome degradation of Aux/ IAA's that are repressors of auxin response factor 7 (ARF7). In the absence of a repressor, ARF7 bound to an auxin response element (AuxRE) in the promoter region of given target genes is allowed to activate transcription. The gene products of these target genes lead to differential cell elongation on the shaded side thus providing a phototropic curvature. It is also seen under blue light simulation there is delocalization of PIN1, a facilitator of polar auxin transport, from basal wall of the plant cell. Arrows and bars represent promotion and repression activities, respectively. 
comparison to wild type) and that certain $G H 3$ family members show a decrease in transcript accumulation in a mutant background. While the evidence supplied is not enough to implicate ARF8 as the transcription factor in sole control of these auxin responsive genes transcription level, it is tempting to hypothesize about a potential role ARF8 may play together with NPH4/ARF7 in relation to these targets. Interestingly, recent data would also suggest potential overlap between MP/ARF5 and NPH4/ARF7 given the even more drastic vascular defects seen in $\mathrm{mp} / \mathrm{nph} 4$ double mutants (Hardtke et al., 2004) However interesting the possibilities for NPH4/ARF7 activity - or for any of the 23 ARF family members - much work remains to determine what the transcriptional targets are for this dynamic transcription factor and its relationship to the phototropic response (Liscum and Reed, 2002).

\section{Center of gravity}

As previously stated, plants maintain optimal growth and development despite environmental conditions that are constantly changing. They accomplish this through integration of the many signals to which they are exposed. This includes changes in the direction of gravity stimulation due to changes in growth axis direction. For example, if you rotate a plant $90^{\circ}$ from its original growth orientation it will perceive $\mathrm{a} 90^{\circ}$ change in the gravity vector and will, over time, reorient its main growth axis so that it is once again growing vertical relative to the gravity vector. This is a gravitropic response to a change in a plant's gravity field and such a response is one way a plant maintains a proper gravitational set-point angle (GPSA) for a given organ. Each plant organ has a specific GPSA that is wholly dependent upon the age of that organ, the type of organ, what stage it is at developmentally and the environment in which the plant is growing (Blancafor and Masson, 2003). When there is a deviation from the GPSA, a plant responds to the stimulation accordingly through differential cellular elongation on the side away from the stimulation. This results in tip curvature and ultimately the GPSA is regained (Firn and Digby, 1997). How does a change in gravity stimulation lead to a differential growth response? First, there must be signal perception or a sensing of the gravity alteration. Second, there must be signal transduction that ultimately leads to the third step; a directional growth response resulting from differential cellular elongation on opposing flanks of the organ in question.

The most popular explanation for how plants perceive changes to their gravity environment is the starch/statolith hypothesis, whereby starch-filled amyloplasts are displaced when the gravity stimulation changes (Kiss et al., 1989). Amyloplasts are found in the columella cells of the root cap (statoliths) and in the endodermal cells of the shoot (statocytes). When laser ablation was used to remove the central root columella cells in Arabidopsis, a large inhibitory effect was seen with respect to root curvature in response to a gravity stimulation (Blancaflor et al., 1998). Genetic studies using mutants that have few or no endodermal cells, lack amyloplasts, or have a problem in sedimentation of amyloplasts have proven to be useful tools in establishing the necessary role of the organelle in a plant's ability to respond to a change in gravity stimulation (for review, see Boonsirichai et al., 2002).

But how does sedimentation of amyloplasts lead to a gravitropic curve? One current idea is that the sedimentation of amyloplasts disrupts the plant cytoskeleton by breaking through the dense local networks of actin microfibrils linked to the plasma membrane (Blancaflor and Masson, 2003). This physical perturbation is proposed to lead to an activation of mechanosensitive ion channels in the plasma membrane (Yoder et al., 2001). Although an initial study in which latrunculin-B was used to disrupt the actin cytoskeleton of maize roots suggested that actin might not be directly involved in the gravitropic response (Yamamoto and Kiss, 2002), a more recent study with this inhibitor indicated that actin is important for gravitropism through modulation of the timing and duration of the response (Blancaflor et al., 2003). Hou and colleagues (2003) have shown that latrunculin-B treated Arabidopsis seedlings exhibit persistent increase lateral auxin accumulation accompanied by an increased duration of alkalinization upon gravistimulation. These results have been interpreted as implicating the cytoskeleton in a regulatory capacity that acts antagonistically to the persistent gravity stimulation by constantly resetting the gravitropic-signaling system (Hou et al., 2003).

In more thoroughly understood signaling systems from animals, signals are often amplified by release of second messengers from intracellular stores, such as the role calcium ions play in Gprotein linked signaling cascades or the role of cyclic AMP in some hormone-induced signaling mechanisms (Alberts et al., 1989). Two ions represent the most likely gravitropic second messengers; namely calcium ions and protons (Blancaflor and Masson, 2003). Cytoplasmic calcium ( $\left[\mathrm{Ca}^{2+}\right]_{\text {cyt }}$ ) fluctuations have been linked to the transduction of a number of signals, both endogenous and exogenous (for a review of the many affects of $\left[\mathrm{Ca}^{2+}\right]_{\text {cyt }}$ in plants, see Sanders et al., 2002). Unfortunately, it is not trivial to monitor changes in intracellular calcium between different stores. Investigators have had to resort to very indirect methods to gauge the impact of $\mathrm{Ca}^{2+}$ on gravitropism such as application of $\mathrm{Ca}^{2+}$ channel blockers or $\mathrm{Ca}^{2+}$ chelators or by removing/altering the function of certain calcium regulatory proteins such as calmodilin-like proteins (for review see Fasano et al., 2002). Recently, however, Plieth and Trewavas (2002) used a luminescent $\mathrm{Ca}^{2+}$ reporter aequorin to look at transient increases in $\left[\mathrm{Ca}^{2+}\right]_{\text {cyt }}$. The intensity of the aequorin luminescence is roughly proportional to the concentration of $\left[\mathrm{Ca}^{2+}\right.$ ]$_{\text {cyt }}$ and thus serves as an excellent tool to look at increases (or decreases) in ion concentration. Plieth and Trewavas (2002) reported that after gravitropic stimulation seedlings exhibit an intense period of luminescence followed by a steady drop off. Interestingly, other mechanical stimulations don't have the same effect on $\left[\mathrm{Ca}^{2+}\right]_{\text {cyt }}$ spiking (Plieth and Trewavas, 2002). Future experiments should include using this biosensor for calcium in conjunction with amyloplast mutants to see whether a link can truly be drawn between the sedimentation of starch molecules and the transient changes in $\left[\mathrm{Ca}^{2+}\right]_{\text {cyt }}$ (Plieth and Trewavas, 2002; Fasano et al., 2002). Inositol-1,4,5-triphosphate (IP3) is another potential second messenger. When using the cereal pulvuni of oat and maize as a system to study gravitropically stimulated ion fluxtuation, IP3 levels were shown to increase as much as five fold within 10 seconds of gravity stimulation (Perera et al., 2001).

Changes in $\mathrm{pH}$ due to fluxes in protons $\left(\mathrm{H}_{+}\right)$has also been implicated as a signaling mechanism in gravitropism. An alkilization of the cytoplasm of columella cells has been shown to occur within minutes of gravity stimulation (Scott and Allen, 1999). This is concomitant with an increase in the acidity of the columella apoplast (Fasano et al., 2001). These pH changes are absent in mutants that fail to make amyloplasts or are less sensitive to gravity 
(Fasano et al., 2001; Blancaflor and Masson, 2003). A change in $\mathrm{pH}$ could depend upon the changing auxin environment as the rates of $\mathrm{pH}$ change seem to follow the rate of auxin transport (Monschausen and Sievers, 2002). Thus, as the auxin environment changes, $\mathrm{pH}$ changes occur in the root columella, perhaps triggering a feedback mechanism that influences the activity and distribution of auxin transporters allowing for signaling amplification.

It appears from the aforementioned studies that signaling is ultimately coupled to auxin transport and response. Based on indirect evidence using auxin-inducible promoter elements, several researches have shown that there does seem to be a lateral flow of auxin that is manifested upon gravity stimulation (Rashotte et al., 2001, Boonsirichai et al., 2003; Ottenschlager et al., 2003). This lateral flow would thus lead to a differential growth response, that results in a gravitropic curvature. As will be discussed below, much of the evidence supporting the role of auxin in gravitropism has come from studies of Arabidopsis mutants.

It should be obvious that for auxin to accumulate in one region of an organ relative to another that new synthesis and/or directional transport of the hormone is required. Since auxin is generally believed to be synthesized only in rapidly dividing regions of the the shoot apex and newly emerged leaves (Bartel, 1997), directional transport must be the mechanism by which lateral auxin accumulation occurs. In unstimulated plants auxin normally travels by two routes from the source of synthesis to rest of the plant where it is utilized: First, via passive diffusion through the phloem cells of the vasculature and second via a polar transport system that links multiple root and shoot tissues. The polar transport system requires transmembrane transporters that can either function to take in auxin from the apoplast (influx carriers) or can serve to shuttle auxin out of a cell (efflux carriers). For an excellent review on auxin transport the reader is referred to a recent review by Friml (2003). The identified influx carriers belong to the AUX/LAX family of proteins related to amino acid transporters carriers (Swarup et al., 2004) while components of the efflux carrier system belong to the AGR/PIN family and MDR-like family of transporters (Noh et al., 2001, 2003). Many members of the PIN family have been implicated in the gravitropic response of roots and shoots (Friml et al., 2002, 2003; Noh et al., 2003; Geldner et al., 2001; Galweiler et al., 1998; Müller et al., 1998), as has AUX1 of the AUX/LAX family of auxin influx carriers (Swarup et al., 2001; Marchant et al. 1999). PIN1 and AUX1 appear to function in transport of auxin from the vasculature to the root tip where PIN4 regulates the channeling of auxin towards more apical columella cells. Once in the columella cells, the presence of AUX1 ensures that auxin will be taken up while the presence of another PIN family member, PIN3, ensures auxin efflux will occur when necessary (Swarup et al., 2004; Friml et al., 2002).

The intracellular localization of PIN3 appears to depend on the root's orientation relative to the gravity vector. PIN3 has been shown to relocalize from a basal to a lateral position within 2 minutes of gravity stimulation (Friml et al., 2002). Interestingly, pin3 mutants show only a small loss of gravitropic responsiveness (Friml et al., 2002). suggesting redundant function for one or more additional PIN family member (Friml et al., 2002). In contrast, aux 1 mutations show dramatic defects in response to gravity stimulation (Chen et al., 1998). Another protein that appears to function in formation of the lateral auxin gradient in response to gravity is ARG1, a ubiquitously expressed J-domain protein (Sedbrook et al., 1999; Boonsirichai et al., 2003). arg-1 mutants fail to redistribute auxin in the root cap when compared to wild-type plants and they also do not show the characteristic change in $\mathrm{pH}$ that is associated with gravitropic stimulation (Boonsirichai et al., 2003). It is currently unknown how ARG1 regulates auxin movement. For example, could ARG1 directly interact with and regulate PIN protein function. One way to address this question would be to examine the localization of PIN family members in an arg1 mutant background.

The sgr (shoot gravitropism) class of mutants exhibit severely impaired (or lack) inflorescence shoot gravitropism and represent another set of mutants that have provided significant new insights into the mechanisms of gravitropic signal response (Fukaki et al., 1996; Yamauchi et al., 1997). Many of the SGR genes identified via mutant phenotype have now been cloned. $S G R 3$ encodes a syntaxin-like protein that appears to be targeted to the prevacuolar and vacuolar compartments (Yano et al., 2003) while SGR4 encodes a SNARE-like protein that is homologous to a yeast protein that is involved in transport of vesicles to the vacuolar compartments (Kato etal., 2002). SGR3 and SGR4 were shown to form a SNARE complex that may be involved in vesicular trafficking to the vacuole (Yano et al., 2003). How the vacuole might be involved in the gravitropic response remains undetermined. However, it is possible that the vacuole might serve as a necessary conduit for auxin redistribution, or the interaction of amyloplasts and vacuole during sedimentation might lead to altered tensions in the vacuolar membranes (Blancaflor and Masson, 2003).

But how does redistributed auxin lead to the expansion of only certain plant cells in response to the gravitropic stimulation? The answer is probably through the acitivity of ARF and Aux/IAA proteins through a mechanism like that discussed for phototropism. The finding that nph4/arf7 mutants show a lack of gravitropic response in the stem is consistent with this notion (Liscum and Briggs, 1995, 1996). Recent microarray studies from the Sederoff lab corroborate this notion of Aux/IAA and ARF activity in the gravitropic response as they found stimulation of $A U X / I A A$ and $S A U R$ family members within 5 minutes of gravity stimulation in the root tip (Kimbrough et al., 2004).

\section{Touch and go}

Thigmotropism is the response of a plant organ to a mechanical stimulation. Intuitively, one can imagine that the gravitropic and thigmotropic responses of roots might be intimately related. In fact, a recent study from Massa and Gilroy (2003) suggest that proper root tip growth requires the integration of both a gravity response and a touch response (Massa and Gilroy, 2003). As with the previously discussed responses, thigmotropism requires perception of a stimulus, a signal transduction cascade that amplifies the signal and finally the ability to respond to the touch stimulation through a differential growth response. In 1990, Bramm and Davis initiated the first comprehensive screen to identify components of the mechanosensory response system in Arabidopsis. From this screen they found a small group of five genes they termed the TOUCH $(\mathrm{TCH})$ family. $\mathrm{TCH} 1$ 
encodes a calmodulin (CaM), while TCH2 and TCH3 encode calmodulin-like genes (Sistrunk et al., 1994). Calmodulin is a highly conserved protein that serves to modulate certain target enzymes under the influence of calcium ions (Allan and Hepler, 1989) and thus one can propose, as was the case for other tropic responses, that $\mathrm{Ca}^{2+}$ may play an important second messenger role (Legue et al., 1997).

$\mathrm{TCH} 3$ represents a particularly interesting $\mathrm{TOUCH}$ protein. First, external calcium application was enough to lead to the increased expression of $\mathrm{TCH}$, suggesting a role for calcium in the feed-back regulation of $\mathrm{TCH} 3$ (Braam, 1992). The fact that $\mathrm{TCH} 3$ accumulates in the cells of the expanding root and shoot and that $\mathrm{TCH} 3$ expression could be artificially induced via exogenous auxin treatment argues for a potential role in cell growth and expansion (Antosiewicz et al., 1995). Recently it has been shown that TCH3 binds to PINOID (PID), a protein serine/ threonine kinase, in a yeast two-hybrid assay (Benjamins et al., 2003). PINOID had previously been shown to be necessary for proper auxin signaling (Bennet et al., 1996; Christensen et al., 2000) and a recent study suggests that it acts as a switch to regulate intracellular localization and the function of the PIN familu of auxin efflux regulators (Friml et al., 2004). TCH3 protein appears to bind PID and regulate the ability of the kinase to phosphorylate substrates in response to changing calcium ion levels (Benjamins et al., 2003). While TCH3 has been shown to be phosphorylated, or at least under the repressive activity of a phosphatase, it is apparently not a substrate for PID itself (Wright et al., 2002; Benjamins et al., 2003). The interaction of a potential calcium-signaling intermediate and a protein involved in regulation of auxin transport represents an attractive link between the two signaling mechanisms most commonly associated with tropic responses. Interestingly, not all hormones appear to play a role in mechanostimulation, which is in accordance with previous findings for other tropic responses.

Unlike $\mathrm{TCH} 1, \mathrm{TCH} 2$ and $\mathrm{TCH} 3$ that encode calmodulin and calmodulin-like proteins, $\mathrm{TCH} 4$ encodes a xyloglucan endotranglucosylase/hydrolase (XTH). TCH4 transcript accumulates rapidly (30 minutes) upon touch stimulation and then declines almost as rapidly (in 1 to 3 hours) (Braam and Davis 1990). There are more than 33 XTH gene family members in Arabidopsis that show relatively varied degrees of sequence homology (Xu et al., 1996; Rose et al., 2002). TCH4 has also been shown to be upregulated by brassinosteroid (BR) and auxin treatment, but not all $X$ TH family members show induction by these hormones (Xu et al., 1995, 1996). Recently it was shown that BR perception is not required for TCH4 expression, leaving open an interesting question as to how BR is affecting TCH4 (lliev et al., 2002).

In vitro, XTHs have been shown to catalyze the cleavage of xyloglucan polymers in the expanding cell wall (Campbell and Braam, 1999; Steele et al., 2001). Xyloglucan is believed to be a tether that holds cellulose microfibrils together in the cell wall, providing tensile strength and restraining cell expansion (Rose et al., 2002). In response to mechanostimulation TCH4 (and/or other XTH family members) could be acting to break the xyloglucan chains, allowing for more elasticity in the wall and thus providing the cell with the capacity to expand and grow with respect to the touch stimulation. These are precisely the kind of wall modification enzymes that might be necessary for a differ- ential growth response under the influence of an auxin gradient, which makes the fact that $\mathrm{TCH} 4$ transcript levels increase in response to auxin application especially interesting. Unfortunately, there is still not much known about the physiological ramifications of these enzymes. There are genome projects underway to try and decipher function for each of the $33 \mathrm{XTH}$ family members (Rose et al., 2002), but much work remains in identifying function of the $\mathrm{TCH}$ family members as well as the XTH family members.

\section{Water, water everywhere ...}

Hydrotropism can be defined as growth or movement in a sessile organism toward or away from water. The best example of this is in plants is the preference of roots for soil with a higher water potential (Takahashi et al., 2002). The idea that plant roots penetrate the soil in search of highest water potential has been long held as truth (Darwin, 1880; Hooker, 1915), however there is very little known about how this actually happens. While we now know that gravity is the driving force behind a root's downward growth and that this growth is modulated by mechansostimulation of soil particles (Massa and Gilroy, 2003), the search for highest water potential is likely playing some role in the integrated growth response. The difficulty in studying hydrotropic growth comes in separation of this response from other tropic responses, gravitropism chiefly among them and drought responses that can occur if plants are water stressed. Further complications arise due to the root cap as the proposed signal integration center for both the gravitropic and hydrotropic responses (Takahashi et al., 2002).

Most studies of hydrotropism have been done using either pea mutants (Takahashi et al., 1991, 1993; Steinmetz et al., 1996), ABA, auxin, or agravitropic mutants of Arabidopsis (Takahashi et al., 2002), or maize roots (Takahashi and Scott, 1993) From early work, it is known that calcium is important for a hydrotropic response, as is auxin and potentially other plant hormones (for a review on early work in hydrotropic studies, see Takahashi, 1997). Recently, however, research has focused on using screens for Arabidopsis mutants that do not show a hydrotropic response making use of a water potential gradient system. To date, two large-scale screens have been initiated in Arabidopsis. The first screen yielded no hydrotropic response 1 ( nhr1) (Eapen et al., 2003), while a second screen has yielded 12 putative mutants termed root hydrotropism (rhy) (Takahashi et al., 2003). Both screens made use of differing water potentials to find mutants that did not show a preference for higher water potential. nhr1 is a semi-dominant mutation that seems to increase root growth sensitivity to abscisic acid (ABA), a plant hormone known to be involved in drought response (Ishitani et al., 1997). Given the embryonic arrest of homozygous nhr1 mutants, it is difficult to assign a potential function to nhr1, although the authors argue for a role in cell proliferation (Eapen et al., 2003). The rhy mutants all show varying degrees of loss of hydrotropic response, but most do not have drastically altered responses to other tropic stimulations, although rhy4 does seem to have a slight reduction in phototropic response, perhaps signaling an area of overlap between these two tropic responses (Kobayashi et al., 2003; Takahashi et al., 2003). To date, none of the twelve rhy mutants has been cloned. Molecular charac- 
terization of the $N H R 1$ and $R H Y$ loci should be informative as to the mechanism of hydrotropic responsiveness and thus their role in growth and development.

\section{Conclusion}

There is still a lot of work to be done before we truly understand how each tropic stimulation impacts a plant and leads to a specific differential growth response. However, recent advances in the various "-omics" should allow for targeted studies that will provide new insights into molecular and biochemical responses of plants exposed to tropic stimuli. The application of mutant analysis to the lesser-studied tropic responses will also shed more light on essential proteins. One thing is certain: As we learn more about each response, we will continue to be amazed by our distant relatives' ability to adapt to changing environments.

\section{All plants move, but they don't usually pull themselves out of the ground and chase you. - Day of the Triffids (1963)}

\section{Acknowledgements \\ We would like to thank members of the Liscum lab for help in preparing this manuscript.}

\section{References}

ALBERTS, B., BRAY, D., LEWIS, J., RAFF, M., ROBERTS, K. and WATSON, J.D. (1989). Molecular Biology of the Cell. 2nd Edition. Garland Publishing, New York. pp. 695-702.

ALLAN, E. and HEPLER, P.K. (1989). Calmodulin and calcium binding proteins. In The Biochemistry of Plants, Vol. 15. Academic Press, New York. pp. 455-484.

ANTOSIEWICZ, D.M., POLISENSKY, D.H. and BRAAM, J. (1995). Cellular localization of the $\mathrm{Ca}{ }^{2+}$ binding TCH3 protein of Arabidopsis. Plant J. 8: 623-636.

BARTEL, B. (1997). Auxin Biosynthesis. Annu. Rev. Plant Physiol. Plant Mol. Biol. 48: $51-66$.

BENNETT, M.J., MARCHANT, A., GREEN, H.G., MAY, S.T., WARD, S.P., MILLNER, P.A., WALKDER, A.R., SCHILZ, B. and FELDMAN, K.A. (1996). Arabidopsis AUX1 gene: a permease-like regulator of root gravitropism. Science 273: 948950.

BENJAMINS, R., GALVAN AMPUDIA, C.S., HOOYKAAS, P.J.J. and OFFRINGA, R. (2003). PINOID mediated signaling involves Calcium-binding proteins. Plant Physiol. 132: 1623-1630.

BLAKSLEE, J. J., BANDYOPADHYAY, A., PEER, W. A., MAKAM, S. N. and MURPHY, A. S. (2004). Relocaozation of the PIN1 auxin efflux facilitation plays a role in phototropic responses. Plant Physiol. 134: 23-31.

BLANCAFLOR, E.B., FASANO J.M. and GILROY, S. (1998), Mapping the functional roles of cap cells in the response of Arabidopsis primary roots to gravity. Plant Physiol. 116: 213-222.

BLANCAFLOR, E.B., HOU, G.C. and MOHAMALAWARI, D.R. (2003). The promotive effect of latrunculin $B$ on maize root gravitropism in concentration dependent. $A d v$. Space Res. 31: 2215-2220.

BLANCAFLOR, E.B. and MASSON, P.H. (2003). Plant gravitropism: unraveling the ups and downs of a complex process. Plant Physiol. 133: 1677-1690.

BOONSIRICHAI, K., SEDBROOK, J.C., CHEN, R., GILROY, S. and MASSON, P.H. (2003). ALTERED RESPONSE TO GRAVITY is a peripheral membrane protein that modulates gravcity-induced cytoplasmic alkilinization and lateral auxin transport in plant statocytes. Plant Cell 15: 2612-2625.

BRAAM, J. and DAVIS, R.W. (1990). Rain-induced, wind-induced and touch-induced expression of calmodulin and calmodulin-related genes in Arabidopsis. Cel/ 60: 357-364.

BRAAM, J. (1992). Regulated expression of the calmodulin-related TCH genes in cultured Arabidopsis cells: Induction by calcium and heat shock. Proc. Natl. Acad.
SCi. USA 89: 3213-3216.

BRIGGS, W.R. and CHRISTIE, J.M. (2002). Phototropins 1 and 2: versatile plant bluelight receptors. Trends Plant Sci. 7: 204-210.

CAMPBELL, P. and BRAAM, J. (1999). In vitro activities of four xyloglucan endotransglycosylases from Arabidopsis. Plant J. 18: 371-382.

CELAYA, R.B. and LISCUM, E. (2005). Phototropins and associated signaling: Providing the power of movement in higher plants. Photochem. Photobiol. 81: 7380.

CHEN, R., HILSON, P., SEDBROOK, J., ROSEN, E., CASPAR, T. and MASSON, P. H. (1998). The Arabidopsis thaliana AGRAVITROPIC 1 gene encodes a component of the polar-auxin-transport efflux carrier. Proc. Natt. Acad. Sci. USA 95: 15112-15117.

CHRISTIE, J.M., REYMOND, P., POWELL, G.K., BERNASCONI, P., RAIBEKAS, A.A., LISCUM, E. and BRIGGS, W.R. (1998). Arabidopsis NPH1: a flavoprotein with the properties of a photoreceptor for phototropism. Science 282: 1698-1701.

CHRISTIE, J. M., SWARTZ, T. E., BOGOMOLNI, R. A. and BRIGGS, W. R. (2002). Phototropin LOV domains exhibit distinct roles in regulating photoreceptor function. Plant J. 32: 205-219.

CHRISTENSEN, S.K., DAGENAIS, N., CHORY, J. and WEIGEL, D. (2000). Regulation of auxin response by the protein kinase PINOID. Cell 100: 469-478.

CHOLODNY, N. (1927). Wuchshormone and tropismen bei den pflanzen. Biol. Zentralbl. 47: 604-626.

COSGROVE, D.J. (2000). New genes and new biological roles for expansins. Curr. Opin. Plant Biol. 3: 73-78.

CROSSON, S., RAJAGOPAL, S. and MOFFAT, K. (2003). The LOV domain family: photoresponsive signaling modules coupled to diverse output domains. Biochemistry 42 : 2-10.

DARWIN, C. (1880). The Power of Movement in Plants. John Murray, London.

EAPEN, D., BARROSO, M.L., CAMPOS, M.E., PONCE, G., CORKIDI, G., DUBROVSKY, J.G. and CASSAB, G.I. (2003). A no hydrotropic response root mutant that responds positively to gravitropism in Arabidopsis. Plant Physiol. 131: 536-546.

FASANO, J.M., SWANSON, S.J., BLANCAFLOR, E.B., DOWD, P.E., KAO, T.H. and GILROY, S. (2001). Changes in root cap pH are required for the gravity response of the Arabidopsis root. Plant Cell 13: 907-921.

FASANO, J.M., MASSA, G.D. and GILROY, S. (2002). Ionic signaling in plant responses to gravity and touch. J. Plant Growth Regul. 21: 71-88.

FINDLAY, G. P. (1984). Nastic Movements, In Advanced Plant Physiology, Wilkins, M.B. (Ed.), Pitman Publishing, Marshfield, MA, pp. 186-200.

FIRN, R.D. DIGBY, J. (1997) Solving the puzzle of gravitropism: has a lost piece been found? Planta 203: S159-S163.

FRIML, J., WISNIEWSKA, J., BENKOVA, E., MENDGEN, K. and PALME, K. (2002). Lateral relocation of auxin efflux regulator PIN3 mediates tropism in Arabidopsis. Nature 415: 806-809.

FRIML, J. (2003). Auxin transport: shaping the plant. Curr. Opin. Plant Biol. 6: 7-12.

FRIML, J., YANG, X., MICHNIEWICZ, M., WEIJERS, D., QUINT, A., TIETZ, O., BENJAMINS, R., OUWERERK, P.B., LJUNG, K., SANDBERG, G., HOOYKAAS, P.J., PALME, K. and OFFRINGA, R. (2004). A PINOID-dependent binary switch in apical-basal PIN polar targeting directs auxin efflux. Science 306: 862-865.

FUKAKI, H., FUJISAWA, H. and TASAKA, M. (1996). Gravitropic response of inflorescence stems in Arabidopsis thaliana. Plant Physiol. 110: 933-943.

GALWEILER, L., GUAN, C., MULLER, A., WISMAN, E., MENDGEN, K., YEPHREMOV, A. and PALME, K. (1998). Regulation of polar auxin transport by AtPIN1 in Arabidopsis vascular tissue. Science 282: 2226-2230.

GELDNER, N., FRIML, J., STIERHOF Y-D, JURGENS, G. and PALME, K. (2001). Auxin transport inhibitors block PIN1 cycling and vesicle trafficking. Nature 413: 425-428.

GRAY, W. M., KEPINSKI, S., ROUSE, D., LEYSER, O. and ESTELLE, M. (2001). Auxin regulates SCF TIR1-dependent degradation of AUX/IAA proteins. Nature 414: 271-276.

HAGEN, G. and GUILFOYLE, T. (2002). Auxin-responsive gene expresion: genes, promoters and regulatory factors. Plant Mol. Biol. 49: 373-385.

HARDTKE, C.S. and BERLETH, T. (1998). The Arabidopsis gene MONOPTEROS encodes a transcription factor mediating axis formation and vascular development. EMBO J. 17: 1405-1411. 
HARDTKE, C.S., CKURSHUMOVA, W., VIDAURRE, D.P., SINGH, S.A., STAMATIOU, G., TIWARI, S.B., HAGEN, G., GUILFOYLE, T.J. and BERLETH, T. (2004). Overlapping and non-redundant functions of the Arabidopsis auxin response factors MONOPTEROS and NONPHOTOTROPIC HYPOCOTYL 4. Development 131: 1089-1100.

HARPER, S.M., NEIL, L.C. and GARDNER, K.H. (2003). Structural basis of a phototropin light switch. Science 301: 1541-1544.

HARPER, S. M., NEIL, L. C., DAY, I. J., HORE, P. J. and GARDNER, K. H. (2004). Conformational changes in a photosensory LOV domain monitored by timeresolved NMR spectroscopy. J. Amer. Chem. Society 126: 3390-3391.

HARPER, R. M., STOWE-EVANS, E. L., LUESSE, D. R., MUTO, H., TATEMATSU, K., WATAHIKI, M. K., YAMAMOTO, K. and LISCUM, E. (2000). The NPH4 locus encodes the auxin response factor ARF7, a conditional regulator of differential growth in aerial Arabidopsis tissue. Plant Cell 12: 757-770.

HOOKER, H.D., JR. (1915). Hydrotropism in roots of Lupinus albus. Ann. Bot.29:265283.

HOU, G., MOHAMALAWARI, D.R. and BLANCAFLOR, E.B. (2003). Enhanced gravitropism of roots with a disrupted cap actin cytoskeleton. Plant Physiol. 131: 1360-1373.

HUALA, E., OELLER, P. W., LISCUM, E., HAN, I-S., LARSEN, E. and BRIGGS, W. (1997). Arabidposis NPH1: A protein kinase with a putative redox-sensing domain. Science 278: 2021- 2023.

ILIEV, A.E., XU, W., POLISENSKY, D.H., OH, M-H., TORISKY, R.S., CLOUSE, S.D. and BRAAM, J. (2002). Transcriptional and posttranscriptional regulation of Arbidopsis $\mathrm{TCH} 4$ expression by diverse stimuli: roles of cis regions and brassinosteroids. Plant Physiol. 130: 770-783.

INADA, S., OHGISHI, M., MAYAMA, T., OKADA, K. and SAKAI, T. (2004). RPT2 is a signal transducer involved in phototropic response and stomatal opening by association with phototropin 1 in Arabidopsis thaliana. Plant Cell 16: 887-896.

ISHITANI, M., XIONG, L., STEVENSON, B. and ZHU, J.K. (1997). Genetic analysis of osmotic and cold stress signal transduction in Arabidopsis: interactions and convergence of abscisic acid-dependent and abscisic acid-independent pathways. Plant Cel/ 9: 1935-1949.

JANOUDI, A-K., KONJEVIC, R., WHITELAM, G., GORDON, W. and POFF, K. L. (1997). Both phytochrome A and phytochrome B are required for the normal expression of phototropism in Arabidopsis thaliana seedlings. Physiol. Plant. 101: 278-282.

JARILLO, J. A., AHMAD, M. and CASHMORE, A. R. (1998). NPL1 (Accession No AF053941): A second member of the NPH1 serine/threonine kinase family of Arabidopsis. Plant Physiol. 117: 719.

KATO, T., MORITA, M.T., FUKAKI, H., YAMAUCHI, Y., UEHERA, M., NIIHAMA, M. and TASAKA, M. (2002). SGR2, a phospholipase-like protein and ZIG/SGR4, a SNARE, are involved in the shoot gravitropism of Arabidopsis. Plant Cell 14: 3346.

KEPINSKI, S. and LEYSER, O. (2004). Auxin-induced SCFTIR1-AUX/IAA interaction involves stable modification of the SCFTIR1 complex. Proc. Natl. Acad. Sci. USA 101: $12381-12386$.

KIMBROUGH, J.M., SALINAS-MONDRAGON, R., BOSS, W.F., BROWN, C.S. and SEDEROFF, H.W. (2004). The fast and transient transcriptional network of gravity and mechanical stimulation in the Arabidopsis rooot apex. Plant Physiol. 136: 2790-2805.

KISS, J.Z., HERTEL, R. and SACK, F.D. (1989). Amyloplasts are necessary for full gravitropis sensitivity in roots of Arabidopsis thaliana. Planta 177: 198-206.

KOBAYASHI, A., KAKIMOTO, Y., FUJII, N. and TAKAHASHI, H. (2003). Physiological and genetic characterization of hydrotropic mutants of Arabidopsis thaliana. Biol. Sci. Space 17: 243-244.

LEGUE, V., BLANCAFLOR, E., WYMER, C., PERBAL, G., FANTIN, D. and GILROY, S. (1997). Cytoplasmic free $\mathrm{Ca}^{-2+}$ in Arabidopsis roots changes in response to touch but not gravity. Plant Physiol. 114: 789-800.

LISCUM, E. and BRIGGS, W. R. (1995). Mutations in the NPH1 locus of Arabidopsis disrupt the perception of phototropic stimuli. Plant Cel/ 7: 473-485.

LISCUM, E. and BRIGGS, W. R. (1996). Mutations in Arabidopsis in potential transduction and response components of the phototropic signaling pathway. Plant Physiol. 112: 291-296.

LISCUM, E. and REED, J. (2002). Genetics of AUX/IAA and ARF action in plant growth and development. Plant Mol. Biol. 49: 387-400.
LISCUM, E. (2002). Phototropism: Mechanisms and outcomes. In The Arabidopsis Book, Somerville, C.R. and Meyerowitz, E.M. (Eds.), American Society of Plant Biologists, Rockville, Maryland, doi/10.1199/tab.0042, http://www.aspb.org/publications/arabidopsis/.

MARCHANT, A., KARGUL, J., MAY, S. T., MULLER, P., DELBARRE, A., PERROTRECHENMANN, C. and BENNETT, M. J. (1999). AUX1 regulates root gravitropism in Arabidopsis by facilitating auxin uptake within root apical tissues. EMBO J.18: 2066-2073.

MASSA, G.D. and GILROY, S. (2003). Touch modulates gravity sensing to regulate the growth of primary roots of Arabidopsis thaliana. Plant J. 33: 435-445.

MONSCHAUSEN, G.B. and SIEVERS, A. (2002). Basipetal propagation of gravityinduced surface $\mathrm{pH}$ changes along primary roots of Lepidium sativum L. Planta 215: 980-988.

MOTCHOULSKI, A. and LISCUM, E. (1999). Arabidopsis NPH3: ANPH1 photoreceptor-interacting protein essential for phototropism. Science 286: 961-964.

MÜLLER, A., GUAN, C., GALWEILER, L., TANZLER, P., HUIJSER, P., MARCHANT, A., PARRY, G., BENNETT, M., WISMAN, E. and PALME, K. (1998). AtPIN2 defines a locus of Arabidopsis for root gravitropism control. EMBO J. 17: 69036911.

NEMHAUSER, J.L., FELDMAN, L.F. and ZAMBRYSKI, P.C. (2000). Auxin and ETTIN in Arabidopsis gynoecium morphogenesis. Development 127: 3877-3888.

$\mathrm{NOH}$, B., MURPHY, A.S. and SPALDING, E.P. (2001). Multidrug resistance-like genes of Arabidopsis required for auxin transport and auxin-mediated developmnet. Plant Cel/13: 2441-2454.

NOH, B., BANDYOPADHYAY, A., PEER, W.A., SPALDING, E.P. and MURPHY, A.S. (2003) Enhanced gravi- and phototropism in plant $m d r$ mutants mislocalizing the auxin efflux protein PIN1. Nature 424: 999-1002.

OKADA, K. and SHIMURA, Y. (1992). Mutational analysis of root gravitropism and phototropism of Arabidopsis thaliana seedlings. Aust. J. Plant Physiol. 19: 439448.

OKADA, K. and SHIMURA, Y. (1994). Genetic analyses of signaling in flower development using Arabidopsis. Plant Mol. Biol. 26: 1357-1377.

OTTENSCHLAGER, I., WOLFF, P., WOLVERTON, C., BHALERO, R.P., SANDBERG, G., ISHIKAWA, H., EVANS, M.L. and PALME, K. (2003) Gravity-regulated differential auxin transport from columella to lateral root cap cells. Proc. Natl. Acad. Sci. USA 100: 2987-2991.

PARKS, B.M., QUAIL, P.H. and HANGARTER, R.P. (1996). Phytochrome A regulates red-light induction of phototropic enhancement in Arabidopsis. Plant Physiol. 110: 155-162.

PERERA, I.Y., HEILMANN, I., CHANG, S.C., BOSS, W.F. and KAUFMAN, P.B. (2001). A role for inositol 1,4,5 triphosphate in gravitropic signaling and the retention of cold-perceived gravistimulation of the oat shoot pulvini. Plant Physiol. 125: 1499-1507.

PLIETH, C. and TREWAVAS, A.J. (2002). Reorientation of seedlings in the earth's gravitational field induces cytosolic calcium transients. Plant Physiol. 129: 786796.

RAMOS, J. A., ZENSER, N., LEYSER, O. and CALLIS, J. (2001). Rapid degradation of AUX/IAA proteins requires conserved amino acids of domain Il and is proteosomedependent. Plant Cell 15: 2349-2360.

RASHOTTE, A. M., DELONG, A. and MUDAY, G. K. (2001). Genetic and chemical reductions in protein phosphatase activity alter auxin transport, gravity response and lateral root growth. Plant Cel/ 13: 1683-1697.

ROSE, J.K.C., BRAAM, J., FRY, S.C. and NISHITANI, K. (2002). The XTH family of enzymes involved in xyloglucan endotransglucosylation and endohydrolysis: current perspectives and a new unifying nomenclature. Plant Cell Physiol. 43: 1421-1435.

SANDERS, D., PELLOUX, J., BROWNLEE, C. and HARPER, J.F. (2002). Calcium at the crossroads of signaling. Plant Cell Suppl. 14: S401-S417.

SAKAI, T., WADA, T., ISHIGURO, S. and OKADA, K. (2000). RPT2: A signal transducer of the phototropic response in Arabidopsis. Plant Cell 12: 225-236.

SAKAI, T., KAGAWA, T., KASAHARA, M., SWARTZ, T. E., CHRISTIE, J. M., BRIGGS, W. R., WADA. M. and OKADA, K. (2001). Arabidopsis nph1 and npl1: Blue light receptors that mediate both phototropism and chloroplast relocation. Proc. Natl. Acad. Sci. USA 98: 6969-6974.

SALOMON, M., LEMPERT, U. and RUDIGER, W. (2004). Dimerization of the plant 
photoreceptor phototropin is probably mediated by the LOV1 domain. FEBS Lett. 572: 8-10.

SCOTT, A.C. and ALLEN, N.S. (1999). Changes in cytosolic pH within Arabidopsis root columella cells play a key role in the early signaling pathway for root gravitropism. Plant Physiol. 121: 1291-1298.

SEDBROOK, J.C., CHEN, R. and MASSON, P. (1999). ARG1 9Altered Response to Gravity) encodes a novel DnaJ-like protein which potentially interacts with the cytoskeleton. Proc. Natl. Acad. Sci. USA 96: 1140-1145.

SESSIONS, A., NEMHAUSER, J.L., MCCOLL, A., RO, J.L., FELDMAN, K.A. and ZAMBRYSKI, P.C. (1997). ETTIN patterns the Arabidopsis floral meristem and reproductive organs. Development 124: 4481-4491.

SISTRUNK, M. L., ANTOSIEWICZ, D.M., PURUGGANAN, M.M. and BRAAM, J. (1994). Arabidopsis TCH3 encodes a novel $\mathrm{Ca}{ }^{2+}$ binding protein and shows environmentally induced and tissue-specific regulation. Plant Cell 6: 1553-1565

STEELE, N.M., SULOVA, Z., CAMPBELL, P., BRAAM, J., FARKAS, V. and FRY, S.C. (2001). Ten isozymes of xyloglucan endotransglycosylase from plant cell walls select and cleave the donor substrate stochastically. Biochem J. 355: 671-679.

STEINMETZ, C., TAKAHASHI, H. and SUGE, H. (1996). Characterization of hydrotropism: the timing of perception and signal movement from the root cap in the agravitropic pea mutant ageotropum. Plant Cell Physiol. 37: 800-805.

STONE, B., ESMON, C. and LISCUM, E. (2004). Phototropins, other photoreceptors and associated signaling: the lead and supporting cast in the control of plant movement responses. Curr. Topics Dev. Biol. 66: 215-237

STOWE-EVANS, E. L., HARPER, R. M., MOTCHOULSKI, A. V. and LISCUM, E. (1998). NPH4, a conditional modulator of auxin-dependent differential growth responses in Arabidopsis. Plant Physiol. 118: 1265-1275.

SWARUP, R., KARGUL, J., MARCHANT, A., ZADIK, D., RAHMAN, A., MILLS, R., YEMM, A., MAY, S., WILLIAMS, L., MILLNER, P., TSURUMI, S., MOORE, I., NAPIER, R., KERR, I.D. and BENNETT, M.J. (2004). Sturcture-function analysis od the presumptive Arabidopsis auxin permease AUX1. Plant Cel/ 16: 3069-3083.

TAKAHASHI, H. and SUGE, H. (1991). Root hydrotropism of an agravitropic pea mutant, ageotropum. Physiol. Plant. 82: 24-31.

TAKAHASHI, H. and SCOTT, T.K. (1993). Intensity of hydrostimulation for the induction of root hydrotropism and it sensing by the root cap. Plant Cell Environ. 16: 99-103.

TAKAHASHI, H (1997). Hydrotropism: the current state of our knowledge. J. Plant Res. 110: 163-169.

TAKAHASHI, N., GOTO, N., OKADA, K. and TAKAHASHI, H. (2002). Hydrotropism in abscisic acid, wavy and gravitropic mutants of Arabidopsis thaliana. Planta 216: 203-211.

TAKAHASHI, N., YAMAZAKI, Y., KOBAYASHI, A., HIGASHITANI, A. and TAKAHASHI, H. (2003). Hydrotropism interacts with gravitropism by degrading amyloplasts in seedling roots of Arabidopsis and Radish. Plant Physiol. 132: 805-810.

TATEMATSU, K., KUMAGI, S., MUTO, H., SATO, A., WATAHIKI, M.K., HARPER, R.M., LISCUM, E. and YAMAMOTO, K.T. (2004). MASSUGU2 encodes Aux/ IAA19, an auxin-regulated protein that functions together with the transcriptional activator NPH4/ARF7 to regulate differential growth responses of hypocotyls and formation of lateral roots in Arabidopsis. Plant Cell 16: 379-393.

TAYLOR, B. L. and ZHULIN, I. B. (1999). PAS domains: internal sensors of oxygen, redox potential and light. Microbiol. Mol. Biol. Rev. 63: 479-506.

THEOLOGIS, A., HUYNH, T.V. and DAVIS, R.W. (1985). Rapid induction of specific mRNAs by auxin in pea epicotyl tissue. j. Mol. Biol. 183: 53-68.

TIAN, C.E., MUTO, H., HIGUCHI, K., MATAMURA, T., TATEMATSU, K., KOSHIBA,
T. and YAMAMOTO, K.T. (2004) Disruption and overexpression of auxin response factor 8 gene of Arabidopsis affect hypocotyl elongation and root growth habit, indicating possible involvement in auxin homeostasis in light conditions. Plant J. 40: 333-343.

TIWARI, S. B., WANG, X. J., HAGEN, G. and GUILFOYLE, T. J. (2001). AUX/IAA proteins are active repressors and their stability and activity are modulated by auxin. Plant Cell 13: 2809-2822.

TIWARI, S. B., HAGEN, G. and GUILFOYLE, T. (2003). The roles of auxin response factor domains in auxin-responsive transcription. Plant Cell 15: 533-543.

TIWARI, S.B., HAGEN, G. and GUILFOYLE, T.J. (2004). Aux/IAA proteins contain a potent transcriptional repression domain. Plant Cell 16: 533-543.

ULMASOV, T., HAGEN, G. and GUILFOYLE, T.J. (1997). ARF1, a transcription factor that binds to auxin response elements. Science 276: 1865-1868.

ULMASOV, T., HAGEN, G. and GUILFOYLE, T.J. (1999). Dimerization and DNA binding of auxin-response factors. Plant J. 19: 309-319.

WATAHIKI, M. K. and YAMAMOTO, K. T. (1997). The massugu1 mutation of Arabidposis identified with failure of auxin-induced growth curvature of hypocotyl confers auxin insensitivity to hypocotyl and leaf. Plant Physiol. 115: 419-426.

WENT, F.W. and THIMANN, K.V. (1937). Phytohormones. Macmillan, New York.

WHIPPO, C. W. and HANGARTER, R. P. (2003). Second positive phototropism results from coordinated co-action of the phototropins and cryptochromes. Plant Physiol. 132: 1-9.

WRIGHT, A.J., KNIGHT, H. and KNIGHT, M.R. (2002). Mechanically stimulated TCH3 gene expression in Arabidopsis involves protein phosphoryylation and EIN6 downstream of calcium. Plant Physiol. 128: 1402-1409.

XU, W., PURUGGANAN, M.M., POLISENSKY, D.H., ANTOSIEWICZ, D.M., FRY, S.C. and BRAAM, J. (1995). Arabidopsis TCH4, regulated by hormones and the environment, encodes a xyloglucan endotransglycosylase. Plant Cell 7: 15551567.

XU, W., CAMPBELL, P., VERGHEESE, A.K. and BRAAM, J. (1996). The Arabidopsis

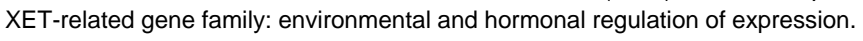
Plant J. 9: 879-889.

YAMAUCHI, Y., FUKAKI, H., FUJISAWA, H. and TASASKA, M. (1997). Mutations in the SGR4, SGR5 and SGR6 loci of Arabidopsis thaliana alter the shoot gravitropism. Plant Cell Physiol. 38: 530-535.

YAMAMOTO, K. and KISS, J.Z. (2002). Disruption of the actin cytoskeleton results in the promotion of gravitropism in inflorescence stems and hypocotyls of Arabidopsis. Plant Physiol. 128: 669-681.

YANO, D., SATO, M., SAITO, C., SATO, M.H., MORITA, M.T. and TASAKA, M. (2003). A SNARE complex containing SGR3/AtVAM3 and ZIG/VTI11 in gravity sensing cells is important for Arabidopsis shoot gravitropism. Proc. Natt. Acad. SCi. USA 100: 8589-8594.

YODER, T.L., ZHENG, H.Q., TODD, P. and STAEHELIN, L.A. (2001). Amyloplast sedimentation dynamics in maize columella cells support a new model for the gravity-sensing apparatus of roots. Plant Physiol. 125: 1045-1060.

ZENSER, N., ELLSMORE, A., LEASURE, C. and CALLIS, J. (2001). Auxin modulates the degredation of AUX/IAA proteins. Proc. Natl. Acad. Sci. USA 98: 1179511800.

ZENSER, N., DREHER, K. A., EDWARDS, S. R. and CALLIS, J. (2003). Acceleration os AUX/IAA proteolysis is specific for auxin and independent of AXR1. PlantJ.35: 285-294.

ZHULIN, L. B. and TAYLOR, B. (1997). PAS domain S-boxes in Archea, bacteria and sensors for oxygen and redox. Trends Biochem. Sci. 22: 331-333. 